\title{
Construction of CT Skills Cultivation Mode in Integrated English Course
}

\author{
Yin Yang \\ Zhejiang Yuexiu University of Foreign Languages, Shaoxing Zhejiang China, 312000 \\ Hazel_295@163.com
}

\begin{abstract}
Keywords: critical thinking (CT); Integrated English Course (IEC); construction; cultivation Abstract: Critical thinking (CT) is the essential goal of learning and central to higher education. Integrated English Course (IEC) provides a good platform to equip students with CT ability. This paper constructs CT skills cultivation mode in Integrated English Course from four steps: constructing interaction platform, cultivating critical reading ability, cultivating critical writing ability and organizing extracurricular research activities. The purpose is to stimulate students to learn new knowledge through thinking in target language and achieve common development in both language skills and cognitive skills.
\end{abstract}

\section{Introduction}

Critical thinking (CT) has long been viewed as a basic survival skill by many scholars ${ }^{[1,2,3]}$. Scholars in education contend that CT is the essential goal of learning and particularly central to higher education ${ }^{[4,5]}$. The development of CT ability is one of the core objectives of higher education in China, and also one of the focuses of foreign language education in recent years. The $5^{\text {th }}$ Advisory Board of Foreign Language and Literature Teaching makes clearly in its "Working Plans" the necessity of cultivating CT skills to promote the innovation and diversified development of the training mode of foreign language talents ${ }^{[6]}$."The National Medium and Long Term Educational Reform and Development Outline (2010-2020)" also advocates the "heuristic, inquiry, discussion type, participatory teaching" as the need of long-term development in education ${ }^{[7]}$. In a critical period of transformation in China's higher education from the epitaxial scale expansion to the connotative quality upgrading, cultivating and developing students' CT ability is not only the educators' bounded duty but also the strategic task of the national long-term development. Integrated English Course (IEC) - integrating the training of students' listening, speaking, reading, writing and translating ability - seems to be a good platform to better equip students with a lifelong ability in CT. Therefore, it is necessary to construct CT skills cultivation mode in integrated English course.

\section{Literature Review of Critical Thinking}

The notion of CT is by no means new; actually it can date back to Socrates, who introduced this way of thinking about two thousand years ago. Although CT has a long history, its definition varies and has never been agreed upon. Some contended that it is skill-based ${ }^{[8,9]}$ while some argued that it must incorporate a dispositional component ${ }^{[10]}$. Although most scholars have agreed that CT engages both skills and dispositions, they still believe that CT skills are teachable and can be reinforced via different techniques and activities implemented in the classroom setting.

In China, the concept CT was first clearly put forward in 1998 when Huang wrote an article called "CT absence" ${ }^{[11]}$ and aroused wide attention in foreign language circle. Many scholars and researchers put forward solutions to cultivate CT skills. At macro level, measures were taken in the transformation of teaching idea, curriculum, textbooks, as well as examination reform, to explore the direction of reform and development for the foreign language education ${ }^{[12,13]}$. At micro level, the construction and inspection of the foreign language students' CT ability paved the way for the study of the students' CT ability in China ${ }^{[14]}$. The cultivation of CT ability should be regarded as an important guide for the development of English major students, which is the basic consensus of the foreign language circle, and also conforms to the strategic goal of the country's long-term development. However, almost twenty years passed, the situation does not seem to have changed 
much. "CT absence" still plagues teachers and students in foreign language circle. Most of the studies in CT only reveal "what is the problem" and give the general guide; there are few studies as to "how to solve the problem" in detail, and rare can the research results be directly applied to the teaching practice. Furthermore, most teachers lack the study of CT theory, and they start researches from personal experiences or teaching experiments, which are not universally applicable. Therefore, it is urgent that we start to consider about what kind of CT skills should be cultivated as well as how to cultivate CT skills in classroom setting.

\section{The Current Teaching in IEC}

Many studies show that the current teaching in IEC pays too much attention to the students' language skills training, ignoring the ability of critical thinking, especially the training of CT ability. In other words, the "CT absence" exists generally, and it is getting worse and worse. As a member of IEC, the author finds that there are some major problems in the teaching of this course. (1) With the ambiguous teaching goal and great influence of unified national examination, many teachers are unaware of the importance of CT cultivation. Their teaching is still test-oriented, striving to be in the top in teaching performance with the high marks of students in examinations, while students' main motivation to learn English is to achieve good marks in final exams and TEM4 examinations. (2) As to the teaching mode and teaching methods, many teachers tend to put too much effort and time on language teaching. Although they mostly recognize the necessity of CT in English teaching, their teaching methods and measures, without official requirements and scientific standards, are usually based on their own understanding, by adopting pair work and group work to organize classroom teaching, but they fail to guide students to explore in-depth problems and organize ideas with their personal experience and knowledge. As to what kind of CT skills should be cultivated, the researches now are still stuck in simple jargons. (3) As to the evaluation system, the test of this course is too focused on the examinations of students' language skills, with no assessment of CT ability. Examination, an invisible baton, guides teachers and students to carry out the teaching of language skills, abandoning the pursuit of other qualities including CT ability, which caused students" "CT absence” objectively.

\section{Construction of CT Skills Cultivation Mode in IEC}

Integrated English Course (IEC), as its name implies, should integrate listening, speaking, reading, writing and translating activities and these activities should be based on the ideological and cultural content, carried by language and driven by problems, to guide students' critical thinking. To realize this purpose, the construction of CT skills cultivation mode can be comprised of the following four steps: (1) constructing interaction platform; (2) cultivating critical reading ability; (3) cultivating critical writing ability; (4) organizing extracurricular research activities.

4.1 Constructing interaction platform. The textbooks of IEC mostly divide the learning units by topics, each unit developing around one topic with activities of listening, speaking, reading, writing, and translating. If the classroom activities are only confined to the practice of these language skills, students will of course lose their interest in English learning. Therefore, it is not appropriate to regard the textbooks as the carrier of language materials, but to dig out the more plentiful content and cultural connotation, so as to make the transformation from dull materials to useful and interesting content. In classroom teaching, teachers need to lead the topics to the daily life of their students and then extend to the hot topics in the society within students' interest driven by critical thinking. The topics in the text and the social reality are then connected to bring out students' inherent need for emotional expression, enabling them to think, compare, discover, judge and explain new issues and feel new things, as well as improving their oral and written expression ability accordingly. Through such human-oriented and CT-driven way, the content in the textbook is put in a larger social and cultural background, and the students' prior knowledge is activated to discover and explain new problems they face. True and effective learning thus comes into being.

4.2 Cultivating critical reading ability. The teaching of reading accounts for a large proportion in 
IEC. For a long time, the teaching methods of reading have paid too much attention to the explanation of language points and the analysis of grammar details, neglecting the training of students' CT ability. The activities in classroom lack the ideological interaction between teachers and students as well as students and students themselves. Our reform is to change the traditional teaching mode by leading students up to the in-depth content, guiding them to read critically, discover the personal meanings and explore the related content. The steps of critical writing are presented in table 1.

Table 1 Three Steps of Critical Reading

\begin{tabular}{|c|c|}
\hline Reading Steps & Orientation \\
\hline Pre-reading & $\begin{array}{l}\text { activate background knowledge - share resources - make cultural } \\
\text { bedding for reading }\end{array}$ \\
\hline in reading & $\begin{array}{l}\text { grasp the theme - master text scheme - infer clues - feel exotic } \\
\text { culture - pick up language features - appreciate writing style }\end{array}$ \\
\hline Post-reading & $\begin{array}{l}\text { Deepen the theme - link the reality - judge the value - exchange } \\
\text { post-reading opinion }\end{array}$ \\
\hline
\end{tabular}

Pre-reading discussion is to activate students' knowledge about a certain topic, and then students share resources to provide cultural basis and interpretation preparation for the construction of meaning. In the process of reading, through explicit teaching, teachers help students grasp the author's narrative or discourse structure, understand social and cultural background, learn about the implied meanings and appreciate the language style. Post-reading discussion aims to further deepen the theme. The text is put under a certain social background, students are inspired to analyze text language, evaluate the author's ideological and cultural values, and put forward their own views.

4.3 Cultivating critical writing ability. In IEC, the teaching effect of writing is not so satisfactory, and writing, as an academic ability, is the weakest part in the students' English skills ${ }^{[15]}$. To a large extent, writing ability is closely related to the critical reading. The texts around a certain topic in each unit provide the materials of thought, language model as well as structure model for writing. Therefore, critical reading and critical writing should be in cohesive relationship. The steps of critical writing are presented in table 2 .

Table 2 Six Steps of Critical Writing

\begin{tabular}{|c|c|}
\hline Writing steps & Orientation \\
\hline critical reading & getting language model and structure model \\
\hline brain storming & exchanging views from multiple perspectives \\
\hline designing & reader consciousness - thematic framework - text pattern \\
\hline initial draft & $\begin{array}{c}\text { putting forward problems - analyzing problems - expressing } \\
\text { opinions }\end{array}$ \\
\hline revision & $\begin{array}{l}\text { exchanging opinions - getting feedback from peers and teachers - } \\
\text { optimizing output }\end{array}$ \\
\hline final draft & sharing output - learning from each other \\
\hline
\end{tabular}

Combining their own experience and social reality, students judge the author's opinion and ideology through critical reading, and form their own standpoint and perspective. And then through peer exchange, students are able to deepen their views from multiple perspectives, and improve their CT ability accordingly. At the same time, teachers need to guide students to explore the structure mode, the argumentation process, the rhetorical devices, as well as the linguistic features of the reading text. During this process, students can develop clear reader-consciousness, and choose appropriate language consciously to express their opinions and attitudes with reference to the model essay in the logic and discourse structure. After the first draft, students can optimize their output through several ways such as teachers' written feedback, peer feedback, and interviews between teacher and students. And then, the final draft can be shared in the class.

4.4 Organizing extracurricular group activities. In the IEC classroom teaching, critical reading 
and research writing are often restricted by class time, so that the depth of discussion is far from enough, and the discussion is often interrupted when class is over. So we need to make full use of extracurricular activities to build the dynamic learning field of interaction between classroom teaching and extracurricular activities.

Teachers design related research topics in the extracurricular group research activities, recommend some feasible methods, and give some guidance and feedback in time while students take charge of topic selection, organization, arrangement, implementation, evaluation and conclusion. In this process, students can adopt and test their cognitive, meta-cognitive, social and affective strategies.

\section{Conclusion and Suggestion}

The construction of CT skills cultivation mode in IEC combines CT skills cultivation and language teaching. Specifically, it improves students' ability of analyzing and solving problems independently through the fusion of CT content and language knowledge, using the language as the carrier. The final goal is to stimulate students to learn new knowledge through thinking in target language and achieve common development in both language skills and cognitive skills. At the same time, the four steps in the construction of CT skills cultivation mode are all around the cultivation of students' autonomous learning ability, which enables the students to take initiative to apply the existing knowledge, life experience and values to independent thinking, rational analysis and accurate judgment.

Students in such IEC class will pay more attention to what is out of the textbook, but on the other hand, they will feel more worried about the course examination. Therefore, in the reform of teaching objectives and teaching methods, it is imperative to make adjustments to the curriculum evaluation methods and means accordingly. Formative assessment mechanism should be adopted to strengthen the innovation of the evaluation. In other words, no matter what form is adopted to evaluate students' study of this course, CT ability needs to enjoy the equal significance as language skills.

\section{Acknowledgements}

This work was financially supported by 2015 Classroom Teaching Reform Project of Shaoxing: Construction of Research Class in Integrated English Course and Cultivation of Students' Critical Thinking Skills.

\section{References}

[1] I. Wright. (2002). Is That Right? Critical Thinking and the Social World of the Young Learner. Toronto: Pippin Publishing.

[2] J. Moon. (2008). Critical Thinking: An Exploration of Theory and Practice. London: Routledge.

[3] M. R. Hashemi \& A. Ghanizadeh. (2012). Critical discourse analysis and critical thinking: An experimental study in an EFL context. System, 40, 37-47.

[4] R. Ennis. (1996). Critical Thinking. New Jersey: Prentice-Hall.

[5] G. Dunne. (2015). Beyond critical thinking to critical being: Criticality in higher education and life. International Journal of Educational Research, 71, 86-99.

[6] M. S. Zhong \& Y. Z. Sun. (2014). Push ahead comprehensive reform and development of teaching in foreign language major with talent cultivation as its center - working plans of the $5^{\text {th }}$ Advisory Board of Foreign Language and Literature Teaching under the Ministry of Education. Foreign Language World, (1), 2-8.

[7] Information on http://www.china.com.cn/policy/txt/2010-03 /01/content_19492625_3.htm 
[8] R. Paul. (1988). Critical Thinking in the Classroom. Teaching K-8, 18, 49-51.

[9] G. B. Watson \& E. M. Glaser. (2002). Watson-Glaser Critical Thinking Appraisal UK. London: The Psychological Corporation.

[10] P. A. Facione, C. A. Giancarlo, N. C. Facione \& J. Gainen. (1995). The Disposition Toward Critical Thinking. Journal of General Education, 44 (1), 1-25.

[11] Y. S. Huang. (1998). Critical Thinking Absence. Foreign Languages and Their Teaching, (7), 1, 19.

[12] Y. S. Huang. (2010). Thoroughly Reforming English Major Courses. Foreign Language World, (1), 11-16.

[13] Y. Z. Sun. (2011). Toward a Critical Thinking-oriented Curriculum for English Majors. Foreign Languages in China. 8 (3), 49-58.

[14] Q. F. Wen, J. Q. Wang, C. R. Zhao, Y. P. Liu \& H. M. Wang. (2009). The Construction of a Conceptual Framework for Assessing Chinese College Students' Critical Thinking Skills. Foreign Language World, (1), 37-43.

[15] Y. S. Huang. (2006). A Good Composition Is Written. Foreign Language World, (5), 13-16. 